\title{
A Study on Sinoatrial Conduction in the Aged
}

\author{
Keiji Ueda, M.D., Chizuko Kamata, M.D., Hiroshi Matsuo, M.D., ${ }^{*}$ \\ Shinichiro OHкawa, M.D., Takao Oктмото, M.D., \\ and Masaya Sugrura, M.D.
}

\section{SUMMARY}

Sinus node response to premature atrial stimulation (PAS) was studied in 30 aged patients (group I: 21 cases without sinus node dysfunction, group II : 9 cases with sick sinus syndrome). Sinoatrial conduction time (SACT) was calculated according to the method reported by Strauss et al.

As coupling interval of PAS decreased, there noted 5 patterns of sinus node response. In Type $A$, return cycle length ( $R C$ ) initially increased (fully compensatory pause) and then became constant; $\mathrm{RC}$ progressively increased either along the compensatory reference line (Type $\mathbf{B}_{1}$ ) or along the less-than-compensatory line (Type $\mathbf{B}_{2}$ ) without being constant. In 2 other cases, RG showed similar pattern as in Type A up to $32-37 \%$ of sinus cycle length where they showed abrupt prolongation below or above the compensatory reference line (Types $\mathrm{C}$ and $\mathrm{D}$, respectively).

The incidence of abnormal response (Types $B_{1}, B_{2}, C$, and D) was high both in group I (38.0\%) and group II $(33.3 \%)$. The calculated SACT in group I showed a high correlation with basic sinus cycle length, while no correlation was observed in group II.

The possible factors influencing return cycle length and significance of frequent observation of abnormal sinus nodal responses in the aged subjects were discussed.

\section{Additional Indexing Words :}

Sick sinus syndrome Sinoatrial conduction time Sinus node automaticity Sinoatrial block

W

ITH the recognition of the prevalence of the syndrome of sinus node dysfunction (sick sinus syndrome), ${ }^{1)-3)}$ a growing interest has been focused on the clinical methods by which sinus node function can be evaluated in normal and abnormal subjects.

Recently, technics of rapid atrial pacing( ${ }^{4), 5}$ and premature atrial stimulation (PAS) $)^{6}$ have been introduced to evaluate sinus node dysfunction. Using

From the Division of Cardiology, Tokyo Metropolitan Geriatric Hospital, 35-2 Sakaecho, Itabashi-ku, Tokyo 173, Japan.

* Second Department of Internal Medicine, Faculty of Medicine, University of Tokyo.

Received for publication April 27, 1976. 
the technique of PAS, we evaluated sinoatrial conduction in 30 aged patients, in whom sinus node dysfunction was relatively common.

\section{Patients And Methods}

Consecutive 30 cases, aged 62 to 90 years, were selected from those scheduled for electrophysiological study, excluding cases with sinus arrhythmias with variation of cycle length exceeding $0.16 \mathrm{sec}$ at the time of the study.

Group I; Twenty-one cases (cases 1 21, 10 males and 11 females) had various types of conduction disturbances, such as atrioventricular block, bundle branch block, or WPW syndrome as listed in Table I, but had no clinical signs of sinus node dysfunction. Their age ranged from 62 to 88 years.

Group II ; Nine cases (cases 22 30, 5 males and 4 females) had clinical presentations to be felt to represent sinus node dysfunction. Six cases had episodes of alternating sinus bradycardia and supraventricular tachycardia (so-called bradycardia-tachycardia syndrome), 2 had episodes of spontaneous sinoatrial block, 1

Table I. Group I

\begin{tabular}{|c|c|c|c|c|c|c|c|}
\hline No. & Name & Age \& & Sex & $\begin{array}{l}\text { Electrocardiographic } \\
\text { Diagnosis }\end{array}$ & $\begin{array}{l}\text { BSCL } \\
\text { (msec) }\end{array}$ & Type & $\begin{array}{l}\text { SACT } \\
(\mathrm{msec})\end{array}$ \\
\hline 1 & I. $T$. & & $\mathrm{F}$ & $3^{\circ} \mathrm{A}-\mathrm{V}$ block & 840 & A & 93 \\
\hline 2 & S. K. & 81 & $M$ & Advanced $A-V$ block & 1,340 & A & 121 \\
\hline 3 & H. T. & & $\mathrm{F}$ & $2^{\circ} \mathrm{A}-\mathrm{V}$ block & 771 & A & 77 \\
\hline 4 & S. M. & 78 & F & WPW syndrome & 608 & A & 58 \\
\hline 5 & K. M. & 70 & $\mathrm{~F}$ & RBBB & 1,112 & A & 106 \\
\hline 6 & Y.A. & 70 & $\mathrm{~F}$ & $\mathrm{RBBB}$ & 934 & $A$ & 145 \\
\hline 7 & S. S. & 88 & M & $3^{\circ} \mathrm{A}-\mathrm{V}$ block & 880 & A & 95 \\
\hline 8 & S. N. & 65 & $\mathbf{M}$ & $3^{\circ} \mathrm{A}-\mathrm{V}$ block & 800 & A & 100 \\
\hline 9 & M. W. & 69 & M & normal & 1,140 & A & 105 \\
\hline 10 & T. N. & & $M$ & normal & 720 & A & 109 \\
\hline 11 & N. M. & 79 & M & $3^{\circ} \mathrm{A}-\mathrm{V}$ block & 1,130 & A & 100 \\
\hline 12 & N. T. & 77 & $\mathrm{~F}$ & CRBBB, LAD & 680 & A & 70 \\
\hline 13 & I. O. & & M & $1^{\circ} \mathrm{A}-\mathrm{V}$ block & 1,100 & $\mathrm{~A}$ & 90 \\
\hline 14 & K. H. & & $\mathrm{F}$ & WPW syndrome & & $\mathrm{B}_{2}$ & \\
\hline 15 & S.O. & & M & $1^{\circ} \mathrm{A}-\mathrm{V}$ block & & $\mathrm{B}_{2}$ & \\
\hline 16 & T. O. & 82 & $\mathrm{~F}$ & $1^{\circ} \mathrm{A}-\mathrm{V}$ block, RBBB & & $\mathrm{B}_{2}$ & \\
\hline 17 & S. N. & 78 & $\mathrm{~F}$ & $3^{\circ} \mathrm{A}-\mathrm{V}$ block & & $\mathrm{B}_{2}$ & \\
\hline 18 & T. H. & 73 & $\mathbf{M}$ & incomplete RBBB & & $\mathrm{B}_{2}$ & \\
\hline 19 & K. H. & 66 & M & $2^{\circ} \mathrm{A}-\mathrm{V}$ block & & $\mathrm{B}_{2}$ & \\
\hline 20 & K. H. & 71 & $\mathrm{~F}$ & WPW syndrome & 1,100 & $\mathrm{C}$ & (111) \\
\hline 21 & Y. U. & 69 & $\mathbf{M}$ & $1^{\circ} \mathrm{A}-\mathrm{V}$ block & 1,000 & $\mathrm{D}$ & $(85)$ \\
\hline
\end{tabular}

BSCL: basic sinus cycle length, SACT : sinoatrial condcution time, RBBB : right bundle branch block, A-V block; atrioventricular block, $M$ : male, $F$ : female 
Table II. Group II (Sick Sinus Syndrome)

\begin{tabular}{|c|c|c|c|c|c|c|}
\hline No. & Name & Age \& Sex & $\begin{array}{c}\text { Electrocardiographic } \\
\text { Diagnosis }\end{array}$ & $\begin{array}{c}\text { BSCL } \\
\text { (msec) }\end{array}$ & Type & $\begin{array}{l}\text { SACT } \\
\text { (msec) }\end{array}$ \\
\hline 22 & T. T. & $73 \mathrm{M}$ & Brady-tachy syndrome & 1,450 & A & 132 \\
\hline 23 & M. I. & $65 \mathrm{M}$ & Sinus bradycardia & 1,653 & A & 145 \\
\hline 24 & T. I. & $66 \mathrm{M}$ & Brady-tachy syndrome & 1,000 & A & 82 \\
\hline 25 & T. G. & $74 \mathrm{M}$ & S-A block & 1,200 & A & 200 \\
\hline 26 & Y.O. & $76 \quad \mathrm{~F}$ & Brady-tachy syndrome & 1,000 & A & 155 \\
\hline 27 & T.U. & $80 \mathrm{~F}$ & S-A block & 674 & A & 110 \\
\hline 28 & S. A. & $77 \mathrm{M}$ & Brady-tachy syndrome & 974 & $\mathrm{~B}_{1}$ & \\
\hline 29 & T. Y. & $90 \mathrm{~F}$ & Brady-tachy syndrome & 1,132 & $\mathrm{~B}_{2}$ & \\
\hline 30 & R. N. & $86 \quad F$ & Brady-tachy syndrome & 964 & $\mathrm{~B}_{2}$ & \\
\hline
\end{tabular}

Brady-tachy syndrome: bradycardia-tachycardia syndrome

with sinus bradycardia with rate less than $40 / \mathrm{min}$ (Table II). Their age ranged from 66 to 90 years.

Methods:

All patients were studied in postabsorptive state and did not receive any cardioactive drugs unless otherwise stated.

A bipolar electrode catheter was inserted via the basilic vein and the tip was placed at the lateral wall of high right atrium. The catheter was used for recording of the intraatrial electrogram to initiate programmable stimulator and for delivering rapid stimuli or a single premature stimulation (PAS) after every fifth spontaneous sinus cycle. Rectangular stimuli of $2 \mathrm{msec}$ in duration and twice diastolic threshold were delivered through the catheter via an isolated transformer (Nihon Koden type MDP-2-DS) with pre-set time delay after the last spontaneous atrial depolarization.

A bipolar or quadripolar electrode catheter was inserted via the femoral vein and was used for recording of electrogram in lower right atrium (RAE) and of His bundle electrogram (HBE).

All the above signals and 3 leads of electrocardiograms (lead I, aVf, and VI) were simultaneously displayed on an Electronics for Medicine multichannel oscillograph and recorded on photographic paper at a speed of 50 or $100 \mathrm{~mm} / \mathrm{sec}$, and also on FM magnetic tape.

Measurements and calculations:

Following time intervals were measured; 1) basic cycle length: the interval between the last 2 sinus $P$ waves before applying PAS, 2) test cycle length: the coupling interval of PAS-induced atrial depolarization, 3) return cycle length: the interval between PAS-induced atrial depolarization and the next spontaneous sinus $P$ wave. The lengths of test cycle and return cycle were normalized by dividing by the basic cycle length.

Normalized return cycle length was plotted as a function of normalized test cycle length in individual case. When PASs were delivered in late atrial diastole, the test cycles were followed by fully compensatory pauses (compensatory zone). When the return cycle length remained constant following earlier PASs (reset zone), 
mean sinoatrial conduction time (SACT) was calculated using previously published principles. ${ }^{6}$ In cases in whom the return cycle length did not show constant level of reset zone, no SACT was obtainable.

The intervals between the PASs and depolarization waves of the lower right atrium on HBE at the shortest test cycle which was accompanied by atrial depolarization were measured and designated as intraatrial conduction time in this study.

\section{Results}

I. Types of sinus node response to PAS

In 13 cases of group I (cases 1-13), PAS elicited in late diastole was followed by return cycles that were fully compensatory (compensatory zone), and progressive shortening of test cycle length resulted in constant duration of return cycle (reset zone), which was slightly greater than one spontaneous sinus cycle length. We have designated this type of response as Type A (Fig. $1-\mathrm{A})$.

In 6 cases of group I (cases 14-19), the plot of normalized return cycle versus normalized test cycle did not show a plateau after the transition from fully compensatory pause, but return cycle was progressively prolonged with increasing prematurity of PASs. The plot then followed a diagonal line which was below and to the left of the compensatory reference line, and this type of response was designated as Type $\mathrm{B}_{2}$ (Fig. 1-C).

In 2 other cases of goup I (cases 20 and 21), return cycle length remained constant with earlier PASs as those in Type A, until the test cycle reached $32 \%$ (case 20 ) or $37 \%$ (case 21 ) of the sinus cycle length where they were

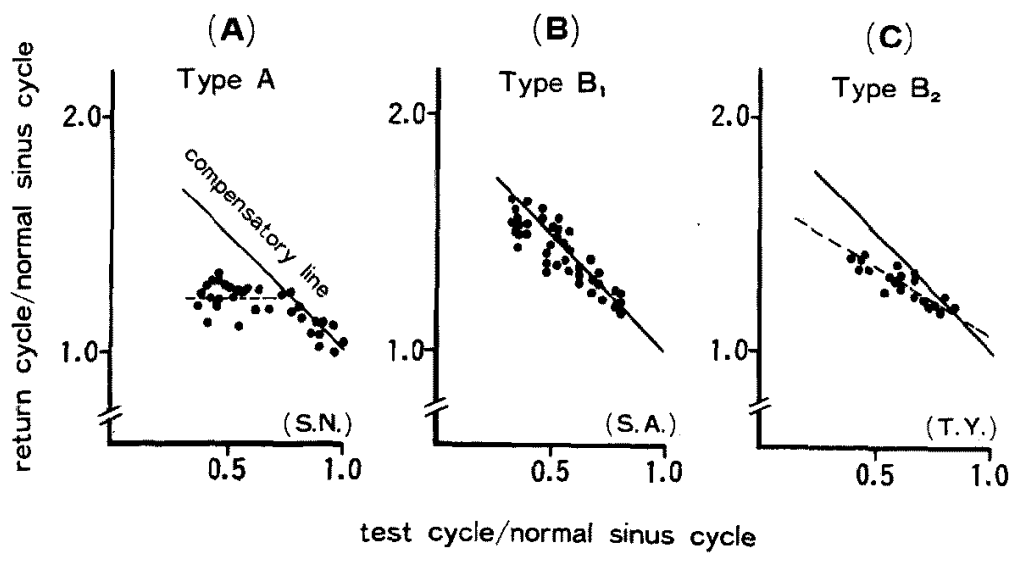

Fig. 1. Types of sinus node response to PAS. (A) Type A response, (B) Type $B_{1}$ response, (C) Type $B_{2}$ response. 


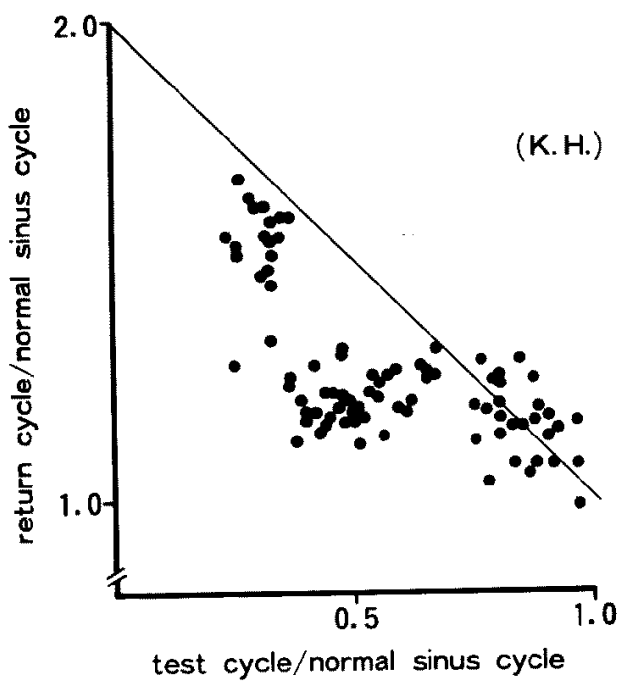

Fig. 2. Type $\mathrm{C}$ response of the sinus node to PAS.

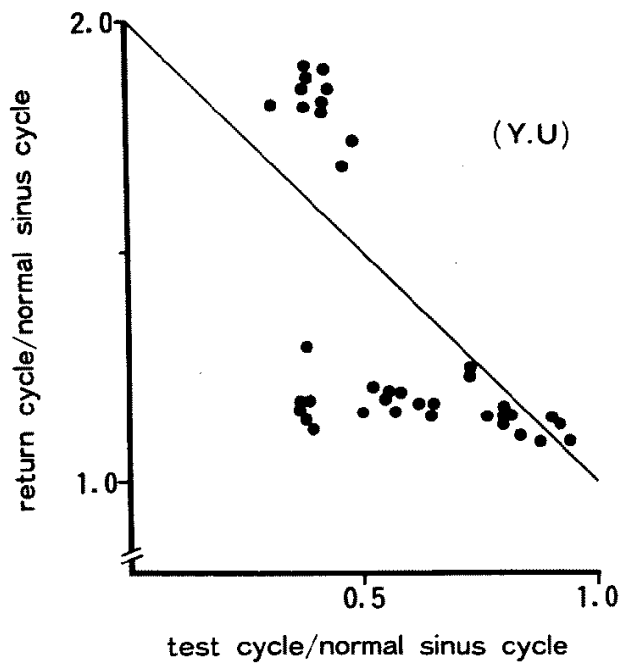

Fig. 3. Type D response of the sinus node to PAS.

abruptly prolonged. In case 20 , the sum of abruptly-prolonged return cycle length and test cycle length was slightly less than twice the basic sinus cycle length (Type C, Fig. 2). In case 21, the sum mentioned above exceeded twice the basic sinus cycle length (Type D, Fig. 3). In cases 20 and 21, intraatrial conduction time was 60 and $50 \mathrm{msec}$, respectively, which were not long, when compared to those for the rest of the cases.

In group II (sick sinus syndrome), 6 cases (cases 22-27) showed Type A response. In 1 case (case 28), the plot of normalized return cycle versus 

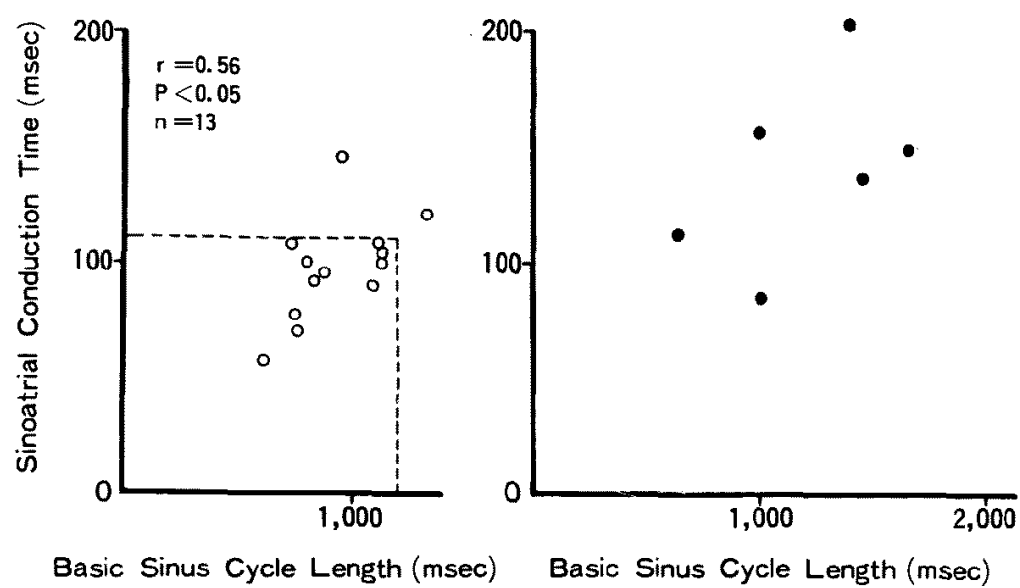

Basic Sinus Cycle Length (msec)

Basic Sinus Cycle Length (msec)

Fig. 4. Relation between sinoatrial conduction time and basic sinus cycle length in cases of Group I (left) and those of Group II (right).

normalized test cycle followed the line of fully compensatory pauses during whole range of test cycles, and this type of response was designated as Type $B_{1}$ (Fig. 1-B). Type $B_{2}$ response above mentioned was observed in 2 cases of group II (cases 29 and 30 ).

II. Calculated sinoatrial conduction time (SACT)

In cases presenting Type A response, SACT ranged from 70 to 145 msec in group I and 82 to $200 \mathrm{msec}$ in group II. In cases 20 (Type G) and 21 (Type D), plateau levels of return cycle length with PASs in the middle of diastole were used for calculation of SACT, which were $111 \mathrm{msec}$ and 85 msec, respectively.

The calculated SACT in group I showed a high correlation with basic sinus cycle length $(\mathrm{r}=0.563, \mathrm{p}<0.05)$ (Fig. 4-A), while no correlation was observed in group II. In 12 cases of group I in whom sinus cycle length was shorter than $1,200 \mathrm{msec}$ (heart rate, more than $50 / \mathrm{min}$ ), SACT was shorter than 1,200 msec (heart rate, more than 50/min), SACT was shorter than $110 \mathrm{msec}$ except in 1 case (case 6). In 1 other case (case 2), prolonged SACT (121 msec) was nearly proportional to a long basic sinus cycle $(1,340$ msec). The average SACT in group I was $97.5 \pm 21.3$ (SD) msec, while the average basic sinus cycle length was $927.3 \pm 210.7$ (SD) msec.

\section{Discussion}

The principles by which SACT was measured in man by Strauss et al6) involve the delivery of PAS through an electrode in high right atrium and analysis of sinus node response to PAS. The studies with this method in 
rabbit, ${ }^{\text {1)-9) }} \mathrm{dog},{ }^{10)}$ and men ${ }^{11)-18}$ ) have been reported. The comparison of these results showed similarities and differences, and basic electrophysiological properties of the sinus node and perinodal fibers have been evaluated in animal studies.

In rabbit hearts, Miller and Strauss ${ }^{9)}$ reported shortening of return cycle length with earlier PASs and this phenomenon was ascribed to shortening of sinus node action potential due to electrotonic interaction. Depression of the sinus node automaticity ${ }^{7}$ and shift of dominant pacemaker to those with slower rate have been also observed in rabbit." Thus comparing the curves obtained in rabbit and human studies, Miller et al $^{9)}$ noted infrequent occurrence of plateau response in rabbit heart. In intact dog hearts Ticzon et al ${ }^{10)}$ could identify 4 zones (compensatory zone, reset zone, interpolation zone, and echo zone) from the plots of return cycles versus test cycles.

In human studies, reported by Strauss et al, ${ }^{6)}$ Engel et al, ${ }^{11}$ and by Sheinman et al, ${ }^{12}$ the transition from a compensatory return cycle to a constant but less than compensatory return cycle, which was common observation in their cases, has been interpreted as signifying the transition from non-capture of the sinus node by PAS. This plateau response was not observed in cases reported by Steinbeck et al.151,16)

The present study on aged patients showed the plateau response with a sharp transition from compensatory zone to reset zone were observed in 21 cases (Type A 19 cases, Type G 1, and Type D 1), of which 15 belonged to Group I and 6 to Group II. The incidence of this occurrence in Groups I and II was $60 \%$ and $66.6 \%$, respectively. Comparable study on the incidence of normal and abnormal responses to PASs among aged patients, to our knowledge, has not been reported.

In the rest of the cases ( 6 of Group I and 3 of Group II), return cycle length was prolonged progressively as the prematurity of the test cycle length was increased. In 1 of them, the plots of return cycle length versus test cycle length with earlier PAS still followed the line of fully compensatory sinoatrial response (Type $B_{1}$ ), which was interpreted as representing first degree sinoatrial block. ${ }^{6}$ ) In other 8 cases, however, the plots followed a diagonal line which was less and to the left of the reference compensatory line (Type $B_{z}$ ), which resembled the cases reported by Steinbeck et al.15),16) They calculated SACT from the return cycle length at the turning point from full compensatory to non-compensatory pause with the assumption that at this point retrograde activation time of sinus node by PAS was shortest. The direct evidence to substantiate this assumption, however, has not been available thus far.

Various factors which influence the return cycle length in noncompen- 
satory zone have been proposed in animal and human studies. Those factors resulting in shortening of return cycle include electrotonic effect of PAS which accompanies shortening of sinus node action potential duration, ${ }^{9)}$ sinus node reentry, ${ }^{81,18)}$ supernormal phase of retrograde atrio-sinus conduction. ${ }^{19)}$ Return cycle length which was identical to the spontaneous sinus cycle length during the whole range of prematurity, possibly due to direct stimulation of the sinus node, were also reported in man. ${ }^{20}$ )

On the other hand, factors resulting in unexpected prolongation of the return cycle length include delayed retrograde conduction from the atrium to the sinus node, $\left.{ }^{6}\right)$ shift to the pacemaker with slower rate, ${ }^{7)}$ and depressant effect of PAS to sinus node automaticity. ${ }^{15), 21)}$

Although species difference may be present, superimposition or counterbalancing of these factors may occur, then it may be difficult to delineate underlying mechanism controlling the changes of the plots in human studies. Although several possibilities may be conceivable to explain Type $B_{2}$ response in this study (Fig. 5), direct evidence to support any of these was not obtained in the present study. Therefore, the curves following either a compensatory or a less-than-compensatory line with earlier PASs preclude an accurate estimation of SACT, thus limiting the application of this method. But, it should be noted that Type $B_{2}$ response was frequently observed in aged patients, notwithstanding the presence or absence of clinical presentation of sinus node dysfunction. This fact may imply that electrophysiological properties of the sinus node or in peri-nodal fiber are frequently impaired in aged patients with other types of conduction disturbances.

The responses observed in cases 20 (Type $\mathrm{C}$ ) and 21 (Type D), in whom sudden, unexpected prolongation of return cycle length with very early PASs, have not been reported in the electrophysiologic study in man with this technique. This "jump up" may represent depressant effect of early PAS on pacemaker automaticity and/or prolonged retrograde atrio-sinus conduction during relative refractory period of the peri-nodal fiber, but not due to delay in intraatrial conduction, because intraatrial conduction was not prolonged.

In the present study, calculated SACT in group I was $97.5 \pm 21.3 \mathrm{msec}$ $(\mathrm{m} \pm \mathrm{SD})$, which is close to normal value of SACT $82 \pm 18.7 \mathrm{msec}$ reported by Seipel et al. ${ }^{17}$ Total sinoatrial conduction time, which is equal to twice the calculated SACT by Strauss's principle, in normal subjects was reported to be $220 \pm 40 \mathrm{msec}$ by Scheinman et $\mathrm{al}^{12)}$ and $169 \pm 91.6 \mathrm{msec}$ by Engel et al. ${ }^{11)}$ These authors ${ }^{11)}$ also reported that prolongation of SACT was frequently observed in patients with sick sinus syndrome.

It should be noted that calculated SACT in goup I showed a high correlation with basic sinus cycle length, indicating the importance of evaluating 

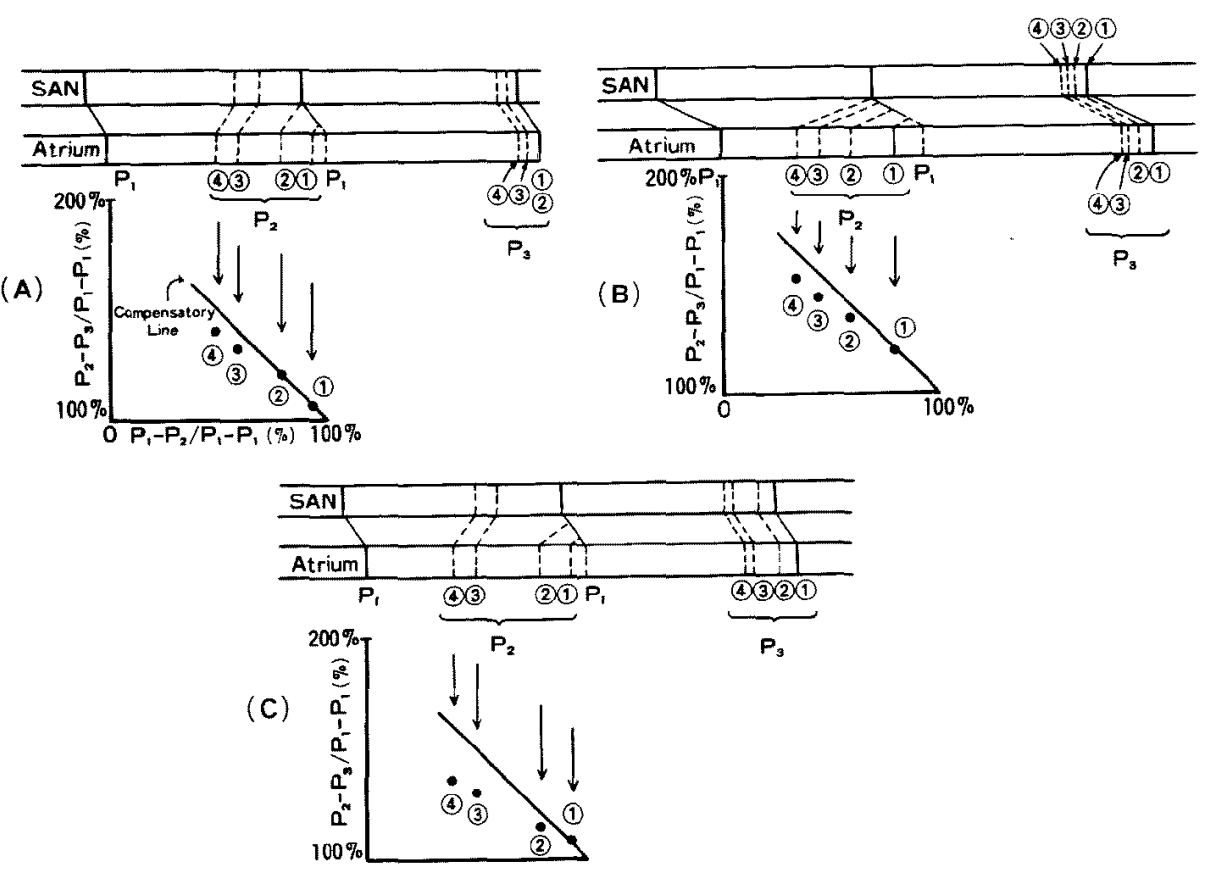

Fig. 5. Possible explanations of Type $B_{2}$ atrial response to premature atrial depolarization. $\quad P_{1}-P_{1}=$ basic cycle length, $P_{2}=$ premature atrial depolarization, $P_{3}=$ atrial return cycle response, $P_{1}-P_{2}=$ test cycle, $P_{2}-P_{3}=$ atrial return cycle, $\mathrm{SAN}=$ sinoatrial node. Compensatory line is the plot of $\left(\mathrm{P}_{1}-\mathrm{P}_{2}\right) /\left(\mathrm{P}_{1}-\mathrm{P}_{1}\right)$ versus $\left(\mathrm{P}_{2}-\mathrm{P}_{3}\right) /\left(\mathrm{P}_{1}-\mathrm{P}_{1}\right)$ when $\left(\mathrm{P}_{1}-\mathrm{P}_{2}\right)+\left(\mathrm{P}_{2}-\mathrm{P}_{9}\right)=$ $2\left(P_{1}-P_{1}\right)$. (A): Compensatory return cycles occur with $P_{2}(1)$ and $P_{2}(2)$. Sinus node capture occur with earlier premature atrial depolarizations $\left(\mathbf{P}_{2}(3)\right.$ and $P_{2}(4)$ ), but less than compensatory return cycle occur because of depressed sinus node automaticity with these earlier atrial depolarizations. (B): In the presence of prolongation of both sinoatrial and atriosinus conduction, premature atrial depolarizations $\left(P_{2}(1)-P_{2}(4)\right)$ do not capture the SAN, but less than compensatory return cycles occur because of the shortening of sinus cycle length due to electrotonic effect of premature atrial depolarizations. (C): Compensatory return cycle occur with $P_{2}(1)$. Less than compensatory return cycle occur with $\mathrm{P}_{2}(2)$ when sinus node capture do not occur, but sinus cycle length is shortened due to electrotonic effect of $\mathrm{P}_{2}$ (3). Sinus node capture occur with $\mathbf{P}_{2}$ (3) and $\mathbf{P}_{2}(4)$, but less than compensatory return cycle occur due to depressive effects on the SAN.

the value of calculated SACT in its relation to basic sinus cycle length in aged subjects. In 5 out of 6 cases of group II, calculated SACT was equal to or exceeded $110 \mathrm{msec}$ and this prolongation was either disproportional to their sinus cycle length in some cases or fairly proportional to their long sinus cycle length in the other. It might be conceivable that changes in autonomic nervous tone in aged patients of group I influences both paccmaker automaticity of sinus node and conduction velocity within sinus node and/or perinodal fibers 
to the same direction. Seipel et $\left.a,^{17}\right)$ however, did not find any relationship between SACT and heart rate. Reifel et al $^{14)}$ and Seipel et $\mathrm{al}^{17)}$ reported in their studies of patients with sinus arrhythmia that SACT varied inversely with sinus cycle length.

Whatever the underlying electrophysiological mechanism may be, observation on the relation between SACT and basic sinus cycle length is of clinical importance. The normal range of SACT as the diagnostic parameter of sinus node dysfunction should be determined on the basis of understanding of the behavior of SACT in various physiological states, which is not available at the present time.

\section{References}

1. Ferrer MI: The sick sinus syndrome. Circulation 46:635, 1973

2. Rubenstein JJ, Schulman CL, Yurchak PM, DeSanctis RW: Clinical spectrum of the sick sinus syndrome. Circulation 36: 5, 1972

3. Kaplan BM, Langendorf R, Lev M, Pick A: Tachycardia-Bradycardia syndrome (so-called "sick sinus syndrome"). Pathology, mechanism and treatment. Am J Cardiol 31: 497, 1973

4. Mandel W, Hayakawa $\mathbf{H}$, Danzig $\mathbf{R}$, Marcus $\mathbf{H S}$ : Evaluation of sinoatrial node function in man by overdrive suppression. Circulation 44:59, 1971

5. Narula OS, Samet P, Javier RP: Significance of the sinus-node recovery time. Circulation 45: 140,1972

6. Strauss HC, Sarnoff AL, Bigger JT Jr, Giardina EGV: Premature stimulation as a key to the understanding of sinoatrial conduction in man. Circulation 47:86, 1973

7. Bonke FIM, Bourman LN, van Rijin HE: Change of cardiac rhythm in the rabbit after an atrial premature beat. Circulat Res 24: 533, 1969

8. Bonke FIM, Bourman LN, Schopman FJG: Effect of an early atrial premature beat on activity of the sinoatrial rhythm in the rabbit. Circulat Res 29: 704, 1971

9. Miller HC, Strauss HC: Measurement of sinoatrial conduction time by premature atrial stimulation in the rabbit. Circulat Res 35: 935, 1974

10. Ticzon AR, Strauss HC, Gallagher JJ, Wallace AG: Sinus node function in the intact dog heart evaluated by premature atrial stimulation and atrial pacing. Am J Cardlol 35: 492, 1975

11. Engel TR, Bond RC, Schaal SF: First degree heart block (abstr). Circulation 48 (Suppl IV) : 161,1973

12. Scheiman MM, Kunkel FW, Peters RW, Schoenfeld PL, Abbott JA: Sinoatrial function and atrial refractoriness (abstr). Circulation 48 (Suppl IV): 215, 1973

13. Bond RC, Engle TR, Schaal SF: The effect of digitalis on sinoatrial conduction time in man (abstr). Am J Cardiol 33: 128, 1974

14. Reifel JA, Bigger JT Jr, Konstam MA: The relationship between sinoatrial conduction time and sinus cycle length during spontaneous sinus arrhythmia in adults. Circulation 50: 924 , 1974

15. Steinbeck G, Körber HJ, Lüderitz B: Die Bestimmung der sinoatrialen Leistungszeit beim Menschen durch gekoppelte Einzelstimulation, Klin Wschr 52: 1151, 1975

16. Steinbeck G, Luderitz B: Comparative study of sinoatrial conduction time and sinus node recovery time. Brit Heart J 37: 956, 1975

17. Seipel L, Breithardt G: Sinusknotenautomatie und Sinoatriale Leitung. Z Kardiol 64: 1014,1975 
18. Childers RW, Arnsdorf MF, de la Fuente DJ, Gambetta M, Svenson R: Sinus nodal echoes. Clinical case report and canine studies. Am J Cardiol 31 : 220, 1973

19. Langendorf $\mathrm{R}$, Lesser ME, Plotkin $\mathrm{P}$, Levin $\mathrm{BD}$ : Atrial parasystole with interpolation. Observation on prolonged sinoatrial conduction. Am Heart J 63:649, 1962

20. Breithardt G, Seipel L, Both A, Loogen F: Direct stimulation of the sinus node in man. Europ J Cardiol 3/4: 323, 1975

21. Dressler W: Prolonged depressing effect of premature supra-ventricular beats. A mechanism causing transient ventricular standstill. Am Heart J 72: 25, 1966 